\title{
Structural Comportment of Extract of Bougainvillea xbuttiana Flower Incorporated in Silica Xerogel Matrix
}

\author{
José Martínez-Mendoza1,2*, Erika Espericueta-González³, Diana Espericueta-González ${ }^{3,4}$, \\ Gerardo Ortega-Zarzosa², Azdrubal Lobo Guerrero ${ }^{3,5}$ \\ ${ }^{1}$ Departamento de Físico-Matemáticas, Universidad Autónoma de San Luis Potosí, San Luis Potosí, México \\ ${ }^{2}$ Facultad de Ciencias, Universidad Autónoma de San Luis Potosí, San Luis Potosí, México \\ ${ }^{3}$ Facultad de Ingeniería, Universidad Autónoma de San Luis Potosí, San Luis Potosí, México \\ ${ }^{4}$ Doctorado Institucional de Ciencia e Ingeniería de Materiales, Universidad Autónoma de \\ San Luis Potosí, San Luis Potosí, México \\ ${ }^{5}$ Instituto de Física, Universidad Autónoma de San Luis Potosí, San Luis Potosí, México \\ Email: *flash@fciencias.uaslp.mx
}

Received 26 February 2016; accepted 19 April 2016; published 22 April 2016

Copyright (C) 2016 by authors and Scientific Research Publishing Inc.

This work is licensed under the Creative Commons Attribution International License (CC BY).

http://creativecommons.org/licenses/by/4.0/

c) (i) Open Access

\begin{abstract}
Measurement of the fluorescence comportment of Bougainvillea xbuttiana flowers embedded in silica xerogels matrix prepared with two different water to tetraethyl-orthosilicate $\left[\mathrm{Si}\left(\mathrm{OC}_{2} \mathrm{H}_{5}\right)_{4}\right]$ ratio molar of 11 and 5, without heat-treatment, we report the grade of biostability of compound. The structural comportment for the PSI and PSII present in Bougainvillea flower is similar to the structural comportment for these photosystems present in leaves when they are incorporated on inorganic matrix such as silica xerogels. The contribution of the natural pigment of this kind of flower such as betalains which consist of betaxanthins and betacyanins, determines their colors contributed in the range of wavelength from about $550 \mathrm{~nm}$ to $660 \mathrm{~nm}$.
\end{abstract}

\section{Keywords}

Betalaine, Chlorophyll, Structure, Biostability, Sol-Gel

\section{Introduction}

Photosynthesis takes place on and in the thylakoid membranes. The proteins and organelles involved in the light

"Corresponding author.

How to cite this paper: Martínez-Mendoza, J., Espericueta-González, E., Espericueta-González, D., Ortega-Zarzosa, G. and Guerrero, A.L. (2016) Structural Comportment of Extract of Bougainvillea xbuttiana Flower Incorporated in Silica Xerogel Matrix. American Journal of Plant Sciences, 7, 828-833. http://dx.doi.org/10.4236/ajps.2016.76078 
reactions are located in and on the thylakoid membrane and in higher plants, this membrane is located in chloroplast.

The higher plants are an efficient system to absorb and transfer the energy through photosynthetic apparatus.

The immobilization of organic pigments on inorganic media may be useful for the design of energy conversion devices [1].

Pigments such as the chlorophyll and betalains present in centrospermae family as the Bougainvillea which basic structural unit is the betalamic acid, are used to be incorporated on inorganic matrix of silica xerogel.

Betalains is a water soluble nitrogenous compound located in the cell vacuoles and is divided into betacyanins and betaxanthins. Betacyanins have a violet coloration whereas bataxanthins have a yellow pigment. Betalains have nutraceutical and they are beneficial to health [2] [3]. Betalains become more and more important in food industry since they are used in the production of yoghurt, ice-cream, jellies, dressings, and cold drinks [4].

Betalains are water-soluble pigments with high antiradical capacity which bestow bright colors in flowers and fruits [5] [6]. Traditionally, betalains have been defined as condensation products of betalamic acid with different amines and amino acids, but the implication of the pigments structure for their properties has been investigated few years ago, and the betalains recovered practically are not studied.

In this work, by measurement of the fluorescence comportment of Bougainvillea xbuttiana flowers embedded in sol-gel amorphous bulk samples prepared with two different water to tetraethyl-orthosilicate $\left[\mathrm{Si}_{(}\left(\mathrm{OC}_{2} \mathrm{H}_{5}\right)_{4}\right]$ ratio molar without heat treatment, we report the grade of biostability of compound.

The higher plants are an efficient system to absorb and transfer the energy through photosynthetic apparatus. This situation can be used to take advantage to prepare materials based in extract of plants for eventually designing efficient optically and electro-optical based sol-gel encapsulated biomolecules [7]. For this, it is necessary to understand the structural evolution of extracted components embedded in silica xerogel matrix, as well as the interaction between the pigments embedded, with the inorganic matrix under heat treatment in which the matrix goes from gel to glass transition, and then correlate with optical properties.

\section{Experimental Method}

Silica xerogels matrix is prepared from the sol-gel polymerization of alcoxides. Hydrolysis occurs when tetraethyl-orthosilicate (TEOS) and water are mixed in a mutual solvent, generally ethanol, according with the following chemical reaction:

$$
\mathrm{Si}\left(\mathrm{OC}_{2} \mathrm{H}_{5}\right)_{4}+x \mathrm{H}_{2} \mathrm{O} \stackrel{\mathrm{C}_{2} \mathrm{H}_{5} \mathrm{OH}}{\longrightarrow} \mathrm{Si}\left(\mathrm{OC}_{2} \mathrm{H}_{5}\right)_{4-x}(\mathrm{OH})_{x}+x \mathrm{C}_{2} \mathrm{H}_{5} \mathrm{OH} .
$$

Condensation occurs between either two silanol or a silanol and a hydroxyl group to form a bridging oxygen or a siloxane group Si-O-Si. A molecule of water or an ethanol molecule is eliminated. The silica tends to form linear molecules that are occasionally cross linked. These molecular chains entangle and form additional branches resulting in a three-dimensional network.

In the sol-gel process the amount of water strongly influences the structure of the final product [8] [9]. Varying the $\mathrm{H}_{2} \mathrm{O}$ /TEOS ratio (R), it is possible to produce structural modifications in the $\mathrm{SiO}_{2}$ glass network without significant deviations from stoichiometry.

We have reported that the low water content, such as the $\mathrm{R}=5$ used in this work, promotes the formation of a glass with a more open structure [10]. The use of values above $R=5$, such as $R=11$, promotes the formation of close structure and thus a three-dimensional network is obtained using this molar ratio [10]. The structural stability of organic species into xerogel matrix are influenced by the silica xerogel network, we evaluate their influence using this two molar ratio of $\mathrm{R}=5$ and $\mathrm{R}=11$ corresponding to formation of open and close structure, respectively.

The organic extract is added before the hydrolysis process occurs thus this aggregates participate in the hydrolysis process and in the condensation process are incorporated in the silica network through a $\pi$-d interaction between organic extract with the empty d orbital of silicon of silica gel matrix, which stabilizes the organic species in silica xerogel [11] [12]. The result is a covalently bonded active molecule within the xerogel structure.

The standard method to extract compound of Bougainvillea is by crude extraction from frozen flower, washed with water, by simple grinding and mixing them with ethanol solvent [12]-[15]. For the extraction a concentration of $8 \mathrm{~g}$ of pink, red, yellow and violet flower of Bougainvillea for $20 \mathrm{ml}$ of ethanol was used. The solution of ethanol and extract was centrifuged at $3000 \mathrm{rpm}$ for $5 \mathrm{~min}$ at ambient temperature, and then filtered with a 
Wattsman filter nr. 1.

In order to obtain the organic composites extract of flowers of Bougainvillea embedded in xerogel matrix, a precursor material composed of tetraethyl-orthosilicate (TEOS), water, ethanol and pigments extract of Bougainvillea flower was prepared. The set of samples were prepared using a constant ethanol to TEOS molar ratio of $4: 1$ and a molar ratio of water to TEOS (R) of $R=11$ and $R=5$. These quantities correspond to a high water/TEOS ratio, needed to enhance the hydrolysis to assure a close amorphous structure for the as-prepared $\mathrm{SiO}_{2}$ powder [10].

The TEOS was dissolved in the ethanol with pigments using magnetic stirring for $15 \mathrm{~min}$ and then the water was added to the ethanol-TEOS solution using magnetic stirring for 10 minutes to form the starting material.

Soft pieces of the gel were obtained after $48 \mathrm{~h}$. Those pieces were ground to form a fine powder.

The emission spectra measurements were carried out in a fluorescence spectrometers by Ocean Optics Inc. Model SF2000 using a reflectance diffused $45^{\circ}$ configuration using a double fiber optic component, excited with an Omnicrome argon ion laser of $532 \mathrm{~nm}$ and filter HNF-532-1.0, in order to obtain the fluorescence contribution due to the photosystem II and the comportment under heat treatment.

\section{Results}

In recent studies has been reported that betaxanthins present emission maxima in the range 570 - $575 \mathrm{~nm}$, the betacyanins non fluoresce and the combination of both compound present emission maximum above $580 \mathrm{~nm}$ [16] [17].

In Figure 1 we show the emission fluorescence spectra for silica xerogel with extract of Bougainvillea flower of pink, red, yellow and violet colors for $\mathrm{R}=11$. In the figure we can observe the typical fluorescence signal of chlorophyll corresponding to photosystem I (PSI) and photosystem II (PSII) located about at $720 \mathrm{~nm}$ and 670 $\mathrm{nm}$, respectively and a fluorescence band for low wavelength that give the peculiar color to the flower located about $580 \mathrm{~nm}$. Thus, the flower contains chloroplast in which occurs photosynthesis.

We can observe that the fluorescent band corresponding to PSI and PSII extended from $650 \mathrm{~nm}$ to $750 \mathrm{~nm}$ is practically the same for the different kind of Bougainvillea flower.

During photosynthesis, once a photon is absorbed by a chlorophyll molecule which is the antennae system of PSI and PSII, the energy from that absorption is quickly transferred to the chloroplast, where it is used to drive chemical processes. When the chlorophyll is extracted, however, the absorbed energy can no longer be trapped, and the chlorophyll remits the energy by fluorescence.

Photosynthesis takes place on and in the thylakoid membranes. The proteins and organelles involved in the light reactions are located in and on the thylakoid membrane and in higher plants, this membrane is located in chloroplast.

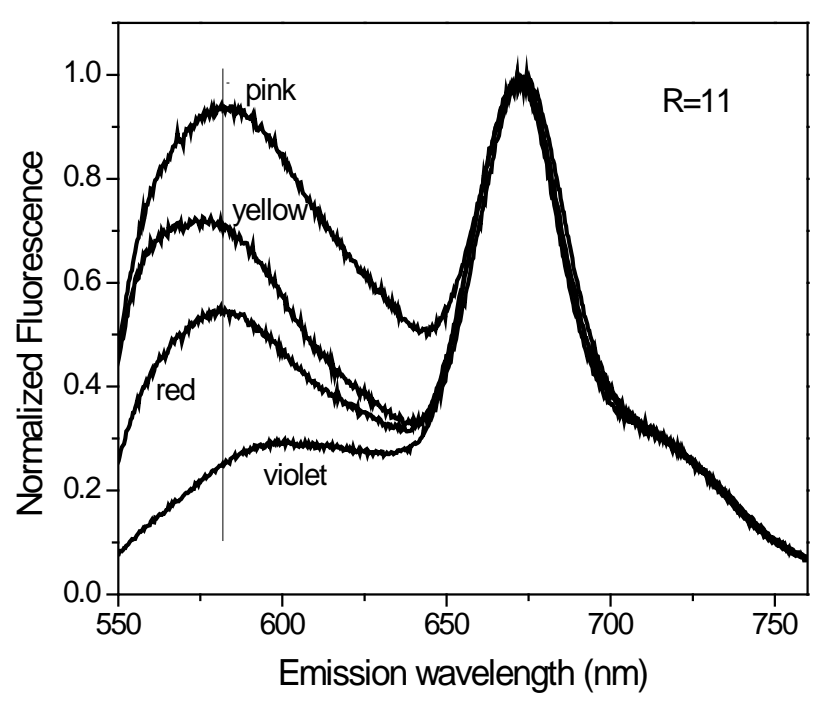

Figure 1. Fluorescent emission spectra of Bougainvillea flower embedded in silica xerogel for $\mathrm{R}=11$, at the indicated colors. 
It is known that organic pigment embedded in silica xerogel present high bio-stability without changes in the structural properties of organic compound [7] [11] [18].

For the fluorescent band located about $580 \mathrm{~nm}$ we observed that the position depend that the particular colour. The position of this band is located at about $600 \mathrm{~nm}$ for the violet colour whereas the position is located at about $573 \mathrm{~nm}$ for the yellow colour, which indicate different array of betalamic acid. This structural difference can be related with the betacyanins and betaxanthines, respectively. The position fluorescent band to red and pink flower is located at $582 \mathrm{~nm}$ and can be consider a combination of the two kinds of betalains compounds. The intensity of these bands depends of the particular colour in which the relative intensity respect to the PSII intensity were 0.93 for the pink colour, 0.71 for the yellow colour, 0.54 for the red colour and 0.28 for the violet colour.

Strucutrally, betaxanthins are defined as immonium condensation products of betalamic acid with amino acids or amines. Traditionally, betacyanins have been defined as condensation products of betalamic acid with ciclo-DOPA, usually glycosylated [19] [20].

The kind of samples for $\mathrm{R}=5$ has a different comportment, in Figure 2 we show the emission fluorescent spectra in which we can observe that the positions of the fluorescent PSI and PSII band, and in general the feature of the band not coincide, compared with Figure 1. We observed different intensities for the band correspond to PSI depending of the colour of the Bougainvillea flower, whereas the position for the PSII band suffers a light blue shifted of $4 \mathrm{~nm}$ for the violet color, respect to the position of the PSII bands of the other three colors and a blue shift for the band assigned to betacyanins of $8 \mathrm{~nm}$. Whereas the position of the corresponding low wavelength band of the other three colors is maintained at the position measurement for the samples prepared with $\mathrm{R}=11$ of Figure 1 .

The relative intensity of these band for $\mathrm{R}=5$, in general are diminish and have values of 0.81 for pink color, 0.40 for yellow color, 0.33 for red color and 0.15 for violet color respect to the PSII intensity.

The blue shift comportment is related with decompose of structure of pigment present in chloroplast. In particular for the PSII the chlorophyll variation indicate denaturation of these species, mainly, the primary conversion of chlorophyll to protein species, as phaeophytene [12] [21].

The denaturation is due to the participation of pigment extracted in the chemical reaction of hydrolysis and condensation. Chlorophyll and betalaine are a pigment that has been chemically altered to provide alkoxysilane functionality. This allows the chlorophyll molecule itself to participate in the hydrolysis and condensation reactions along with the other alkoxide precursor. In particular betalaine are water soluble and to form crosslink for $\mathrm{SiO}_{2}$ is needed high water to TEOS ratio, thus for $\mathrm{R}=11$ contribute to structural bio-stability for the pigment embedded in silica xerogel.

Thus, the water to TEOS ratio molar is determinant to obtain bio-stability of the pigments embedded in silica

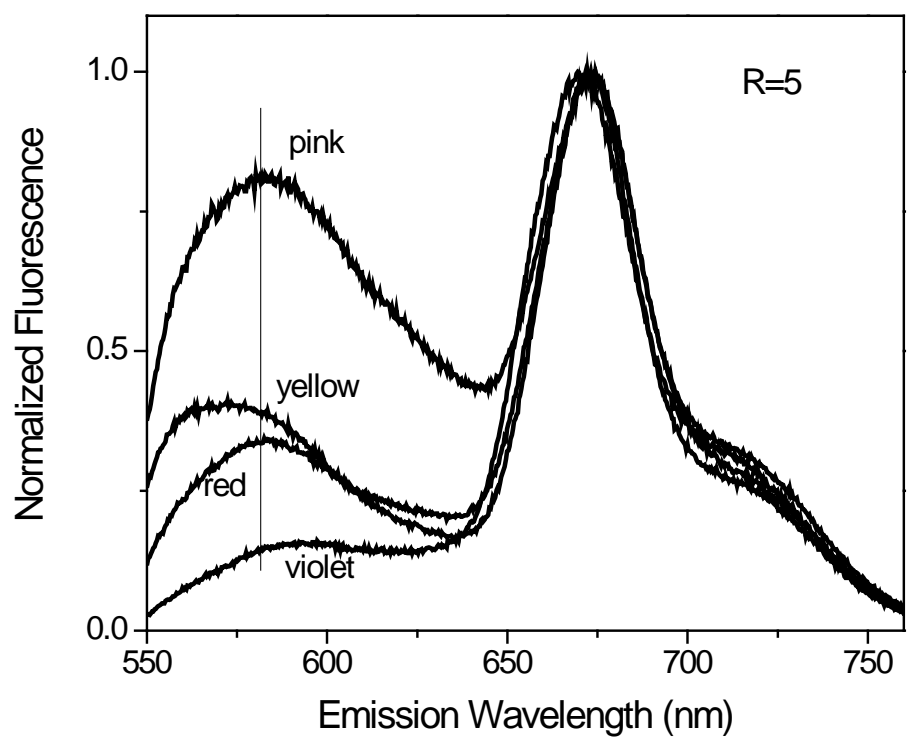

Figure 2. Fluorescent emission spectra of Bougainvillea flower embedded in silica xerogel for $\mathrm{R}=5$, at the indicated colors. 
xerogels, for which required high values of R's to assure the complete hydrolysis and condensation in the sol-gel reaction and minimizing the interaction with the matrix of the pigment incorporated.

A complete analysis for the conditions of regulation of this interaction, i.e. in term of heat treatment, are necessary and are in course.

The structural comportment for the PSI and PSII present in Bougainvillea flower are similar to the structural comportment for these photosystems present in leaves when are incorporated on inorganic matrix such silica xerogels [7] [15]. The denaturation of this photosystems related with chlorophyll decomposition in different proteins, generating fluorescence quenching centers at about $580 \mathrm{~nm}$, must be present in Bougainvillea flower, among, the contribution of betalains, the natural pigment of this kind of flower, whose content of betaxanthins and betacyanins, which determine their colors, contributed in the same range of wavelength from about $550 \mathrm{~nm}$ to $660 \mathrm{~nm}$.

The components extracted of Bougainvillea flower include the chlorophyll. The chlorophyll is the component in photosynthesis that traps the solar energy so that it can be used to drive the production of carbohydrates from carbon dioxide and water. In plants the chlorophyll exists in two forms called chlorophyll $a$ and $b$.

During photosynthesis, once a photon is absorbed by a chlorophyll molecule which is the antennae system of PSI and PSII, the energy from that absorption is quickly transferred to the chloroplast, where it is used to drive chemical processes. When the chlorophyll is extracted from flowers, however, the absorbed energy can no longer be trapped, and the chlorophyll remits the energy by fluorescence.

The comportment of PSII gives us information about the biostability of the compound. The formation parameter used to the formation of extract of flower embedded in silica xerogel matrix, such the water to TEOS ratio (R), are parameter that assure biostability for the chlorophyll species content as in the compound prepared in present study. In previous works, we have demonstrate that there is no significant change of fluorescence of chlorophyll species entrapped in silica xerogel up to 36 months kept in light and weather conditions, revealing no change in chlorophyll structure [11] [18]; thus the PSII remain structurally same in silica xerogel over a very long period of time. In particular, the maximum position of fluorescence of the PSII no change in terms of sol-gel aging time. Thus, we can assure that the compound remaining bioactive over a very long period of time.

The connection that occurs between the two resonant systems, betalamic acid and the aromatic ring dihydroxyphenylalanine cycle conduce that the betacyanin do not fluoresce. However, when this is incorporate on inorganic matrix a fluorescent band of low intensity is observe at wavelength above $600 \mathrm{~nm}$ (violet curve in Figure 1 and Figure 2). For the compound prepared with $\mathrm{R}=11$ the intensity of this band is only $28 \%$ relative to the maximum corresponding to PSII (Figure 1), whereas the intensity of this band is $15 \%$ relative to the maximum for compound prepared with $\mathrm{R}=5$.

\section{Conclusion}

In conclusion, extract of Bougainvillea xbuttiana flowers embedded in silica xerogel matrix presents a higher PSII biostability for samples prepared with a high water to TEOS molar ratio of $\mathrm{R}=11$, in comparison with ratio molar of $\mathrm{R}=5$, where due participation of chlorophyll content of Bougainvillea in the chemical process of hydrolysys and condensation, a variation of the PSII is presented, which altered the relative intensity for the fluorescent band of batalaine, correlated with the color of flower

\section{References}

[1] Furukawa, H., Inoue, N., Watanabe, T. and Kuroda, K., (2005) Silica Mesostructured Films and Photocurrent Generation. Langmuir, 21, 3992. http://dx.doi.org/10.1021/la047845z

[2] Escribano, J., Pedreño, M.A., García-Carmona, F. and Muñoz, R. (1998) Characterization of the Antiradical Activity of Betalains from Beta vulgaris L. Roots. Phytochemical Analysis, 9, 124-127. http://dx.doi.org/10.1002/(SICI)1099-1565(199805/06)9:3<124::AID-PCA401>3.0.CO;2-0

[3] Stintzing, F.C. and Carle, R. (2004) Functional Properties of Anthocyanins and Betalains in Plants, Food, and in Human Nutrition. Trends in Food Science \& Technology, 15, 19-38. http://dx.doi.org/10.1016/j.tifs.2003.07.004

[4] Spears, K. (1988) Developments in Food Colourings: The Natural Alternative. Trends in Biotechnology, 6, $1973-1980$. http://dx.doi.org/10.1016/0167-7799(88)90126-6

[5] Lu, X., Wang, Y. and Zhang, Z. (2009) Radioprotective Activity of Betalains from Red Beets in Mice Exposed to Gamma Irradiation. European Journal of Pharmacology, 615, 223-227. http://dx.doi.org/10.1016/j.ejphar.2009.04.064 
[6] Moreno, D.A., García-Viguera, C., Gil, J.I. and Gil-Izquierdo, A. (2008) Betalains in the Era of Global Agri-Food Science, Technology and Nutritional Health. Phytochemistry Reviews, 7, 261-280. http://dx.doi.org/10.1007/s11101-007-9084-y

[7] Vázquez-Durán, A., Araujo-Andrade, C., Martínez-Castañón, G., Ortega-Zarzosa, G., Ruiz, F. and Martínez, J.R. (2006) Spectral Characterization of Chlorophyll Fluorescence in Extract of Barley Leaves Embedded in Silica Xerogel Matrix. Journal of Sol-Gel Science and Technology, 39, 223. http://dx.doi.org/10.1007/s10971-006-7877-x

[8] Sakka, S. and Kamiya, K. (1982) The Sol-Gel Transition in the Hydrolysis of Metal Alkoxides in Relation to the Formation of Glass Fibers and Films. Journal of Non-Crystalline Solids, 48, 31. http://dx.doi.org/10.1016/0022-3093(82)90244-7

[9] Duran, A., Serna, C., Fornes, V. and Fernández-Navarro, J.M. (1986) Structural Considerations about SiO2 Glasses Prepared by Sol-Gel. Journal of Non-Crystalline Solids, 82, 69. http://dx.doi.org/10.1016/0022-3093(86)90112-2

[10] Martínez, J.R., Ruiz, F., Vorobiev, Y.V., Pérez-Robles, F. and González-Hernández, J. (1998) Infrared Spectroscopy Analysis of the Local Atomic Structure in Silica Prepared by Sol-Gel. The Journal of Chemical Physics, 109, 7511. http://dx.doi.org/10.1063/1.477374

[11] Espericueta, E., Martínez, J.R., Ortega-Zarzosa, G. and, González-Hernández, J. (2010) Blue-Shifted Fluorescence Spectrum in Silica Xerogels with Incorporation of Extract's Leaves. Journal of Sol-Gel Science and Technology, 56, 114-120. http://dx.doi.org/10.1007/s10971-010-2283-9

[12] Manna, J.S., Basu, S., Mitra, M.K., Mukherjee, S. and Das, G.Ch. (2009) Study on the Biostability of Chlorophyll a Entrapped in Silica Gel Nanomatrix. Journal of Materials Science: Materials in Electronics, 20, 1068-1072. http://dx.doi.org/10.1007/s10854-008-9827-6

[13] Killedar, S., Pawar, A., Nadaf, S., Nale, A., Tamboli, U. and Pishawikar, S. (2014) Novel Analytical Method Development for Some Amide Group Containing Drugs Using Bougainvillea spectabilis Bract Extracts. Asian Pacific Journal of Tropical Medicine, 7, S560-S567. http://dx.doi.org/10.1016/S1995-7645(14)60290-X

[14] Kumara Swamy, M., Sudipta, K.M., Lokesh, P., M. Neeki, A., Rashmi, W., S. Bhaumik, H., S. Darshil, H., Vijay, R. and Kashyap, S.S.N. (2012) Phytochemical Screening and in Vitro Antimicrobial Activity of Bougainvillea spectabilis Flower Extracts. International Journal of Phytomedicine, 4, 375-379.

[15] Arteaga Figueroa, L., Barbosa Navarro, L., Patiño Vera, M. and Petricevich, V.L. (2014) Antioxidant Activity, Total Phenolic and Flavonoid Contents, and Cytotoxicity Evaluation of Bougainvillea xbuttiana. International Journal of Pharmacy and Pharmaceutical Sciences, 6, 497-502.

[16] Gandía-Herrero, F., Escribano, J. and García-Carmona, F. (2010) Structural Implications on Color, Fluorescence, and Antiradical Activity in Betalains. Planta, 232, 449-460. http://dx.doi.org/10.1007/s00425-010-1191-0

[17] Gandía-Herrero, F., García-Carmona, F. and Escribano, J. (2005) Floral Fluorescence Effect, Brief Communications. Nature, 437, 334. http://dx.doi.org/10.1038/437334a

[18] Martínez, J.R., Espericueta, E. and Ortega-Zarzosa, G. (2011) Effect of Aging on Chlorophyll Species Embedded in Silica Xerogels Matrix. New Journal of Glass and Ceramics, 1, 7-12. http://www.SciRP.org/journal/njgc http://dx.doi.org/10.4236/njgc.2011.11002

[19] Piattelli, M. (1981) The Betalains: Structure, Biosynthesis and Chemical Taxonomy. In: Conn, E.E., Ed., The Biochemistry of Plants, Vol. 7, Academic Press, New York, 557-575.

[20] Strack, D., Vogt, T. and Schliemann, W. (2003) Recent Advances in Betalain Research. Phytochemistry, 62, $247-269$. http://dx.doi.org/10.1016/S0031-9422(02)00564-2

[21] García Sánchez, M.A., Tello, S.R., Sosa, R. and Campero, A. (2006) Fluorescent Porphyrins Trapped in Monolithic SiO2 Gels. Journal of Sol-Gel Science and Technology, 37, 93. http://dx.doi.org/10.1007/s10971-006-6425-z 